\title{
FEMORAL ANTEVERSION IN THE RABBIT
}

\author{
JOHN A. WILKINSON, LONDON, ENGLAND \\ From the Institute of Orthopaedics, Royal National Orthopaedic Hospital, London and Stanmore
}

Success in the conservative treatment of congenital dislocation of the hip demands concentric reduction of the dislocation and the maintenance of this reduction for a period in which the acetabulum can recover from its dysplastic state.

Controversy still exists on the most effective method of reduction. It has, however, been shown that gradual reduction by traction and abduction of both legs (whether on a bed or on a frame) lowers the incidence of epiphysial fragmentation (Somerville and Scott 1957; Mackenzie, Seddon and Trevor 1960; Wilkinson and Carter 1960).

Two common positions are used to maintain reduction of the dislocated hip and encourage acetabular development. In both the hips are abducted. In one they are also flexed and held in the neutral position, in line with the trunk (Lorenz position). In the other they are held in medial rotation (Batchelor position).

The purpose of this investigation was to observe the effect of splinting the hind limbs of immature animals in different positions, with particular reference to rotation. These observations are recorded and their significance is discussed.

\section{EXPERIMENTAL TECHNIQUES}

Young rabbits six to eight weeks old were used for the experiments. At this age their hips are well developed and are almost replicas of human hips. The normal posture of their hind limbs-in flexion, abduction and lateral rotation-resembles the human prenatal and neonatal posture. It was first necessary to determine the normal degree of femoral anteversion in rabbits at different ages. A series of femora from rabbits of different ages were obtained and photographed (Fig. 1). The degree of femoral anteversion was measured by fixing the femoral condyles on a horizontal plane and measuring the angle of the femoral neck to this plane. This is similar to clinical methods. At birth there were 10 degrees of anteversion in the rabbit's femur; this had disappeared by the eighth week and by the time the animal was skeletally mature at twenty-four months, 10-15 degrees of retroversion had developed (Fig. 2, Table I). The normal range having been established, it was then possible to compare the different degrees of anteversion and retroversion produced experimentally by splinting the lower limbs of the growing rabbit in abnormal positions.

Splinting both hind limbs of a rabbit prevents the animal from moving about its pen. Consequently only one hind limb was splinted. The left limb was immobilised in a padded plaster-of-Paris spica in all the experiments. The ankle was fixed at a right angle and the foot was used as a lever to produce rotational strain on the limb and also to hold it in abnormal position. Torsion was thus applied to the full length of the femur. The effective degree of torsion was reduced by pelvic rotation within the plaster spica. This was partly overcome by changing the plaster every two weeks, under intravenous Nembutal anaesthesia. The clinical method of splinting both limbs with a cross-bar is more effective because rotation of the pelvis is prevented.

\section{SIMPLE ROTATIONAL EXPERIMENTS}

These experiments are divided into three groups.

In the first group are included all animals in which the effects of medial rotation were studied. One hip was held in 60 degrees abduction, full extension and full medial rotation; 


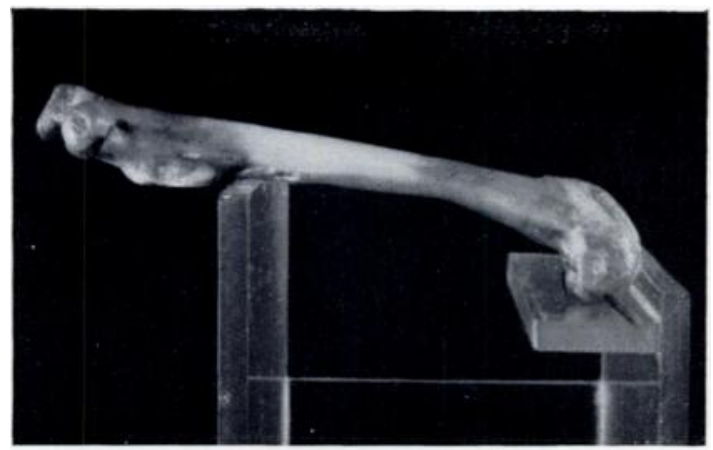

Fig. 1

Lateral view of stand and mounted femur. The condyles rest on a horizontal shelf which is taken as a base line to measure the angle of the femoral neck in assessing both anteversion and retroversion.

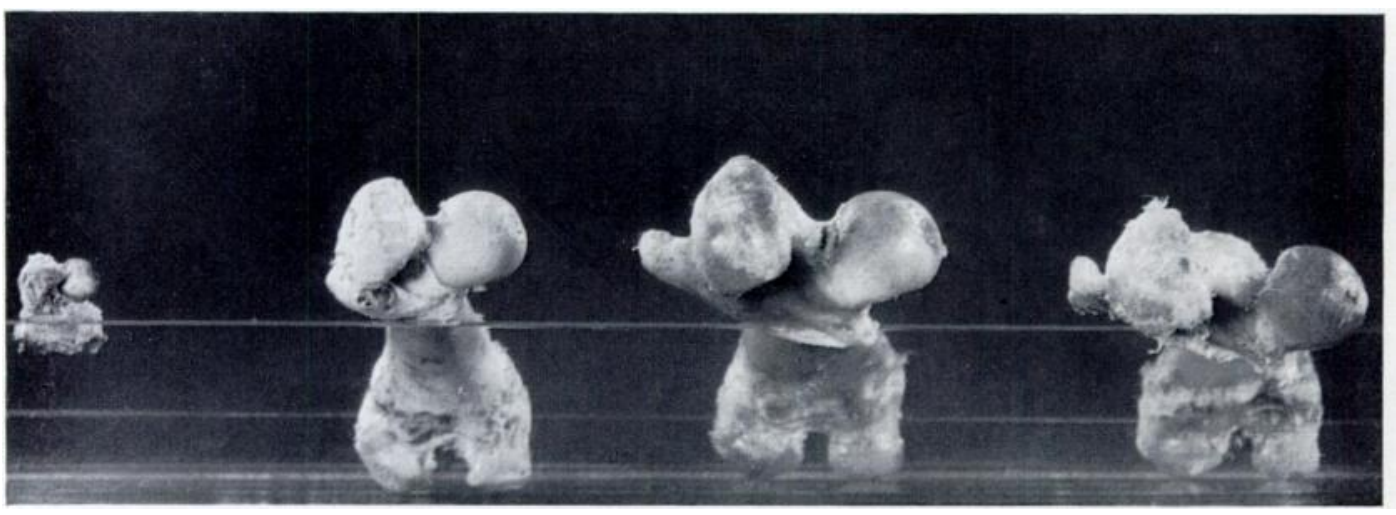

Fig. 2

Femora demonstrating development of femoral rotation in the normal rabbit.

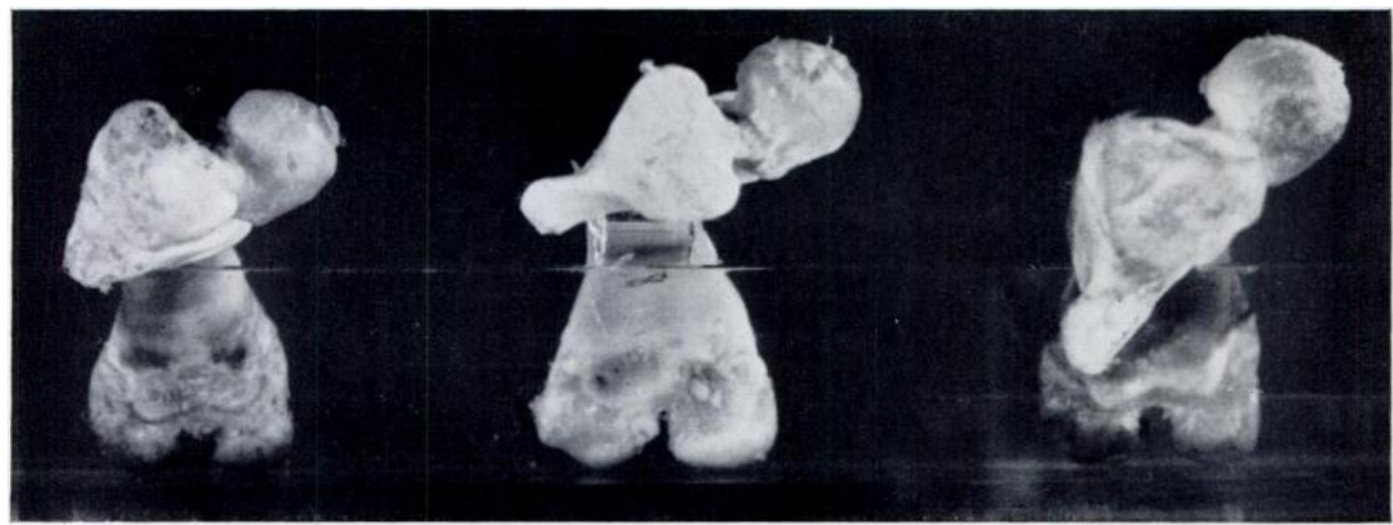

Fig. 3

Femoral anteversion produced by medial rotation splint. (From left to right: Rabbits Nos. $2.318,149$. )

VOL. 44 B, NO. 2, MAY 1962 
TABLE I

The Development of Femoral Rotation IN THE NORMal RabBIT

\begin{tabular}{|lc|}
\hline Age & Degrees of anteversion \\
\hline 5 days & 10 \\
6 weeks & 0 \\
16 weeks & -10 (retroversion) \\
28 months & -15 (retroversion) \\
\hline
\end{tabular}

TABLE II

Results of Splinting in Medial Rotation

\begin{tabular}{|c|c|c|c|}
\hline \multirow{2}{*}{ Rabbit } & \multirow{2}{*}{$\begin{array}{l}\text { Duration of } \\
\text { splintage } \\
\text { (weeks) }\end{array}$} & \multicolumn{2}{|c|}{ Degrees of anteversion } \\
\hline & & Splinted leg & Opposite leg \\
\hline 3 & 4 & 15 & -15 \\
\hline 2 & 5 & 30 & -15 \\
\hline 318 & 10 & 40 & -5 \\
\hline 317 & 12 & 45 & 0 \\
\hline 149 & 15 & 55 & 20 \\
\hline
\end{tabular}

TABLE III

Results of Splinting in Lateral Rotation

\begin{tabular}{|l|l|}
\hline Rabbit & $\begin{array}{c}\text { Duration of } \\
\text { splintage } \\
\text { (weeks) }\end{array}$ \\
$\frac{184}{185} \frac{11}{11} \frac{\text { Degrees of retroversion }}{\text { Splinted leg }}$ & $\frac{25}{25} \frac{10}{10}$ \\
\hline
\end{tabular}

TABLE IV

Results of Splinting in the Lorenz Position

\begin{tabular}{|c|c|c|c|}
\hline \multirow{2}{*}{ Rabbit } & \multirow{2}{*}{$\begin{array}{c}\text { Duration of } \\
\text { splintage } \\
\text { (weeks) }\end{array}$} & \multicolumn{2}{|c|}{ Degrees of retroversion } \\
\hline & & Splinted leg & Opposite leg \\
\hline 172 & 12 & 0 & 45 \\
\hline 173 & 14 & 5 & 40 \\
\hline 301 & 14 & $\begin{array}{c}-5 \\
\text { (anteverted) }\end{array}$ & 55 \\
\hline
\end{tabular}


the latter was increased at each change of plaster. The results of these experiments are shown in Figure 3 and Table II; the longer the medial rotation was maintained, the greater was the degree of anteversion in the splinted femur. If the hip was adducted, instead of abducted,

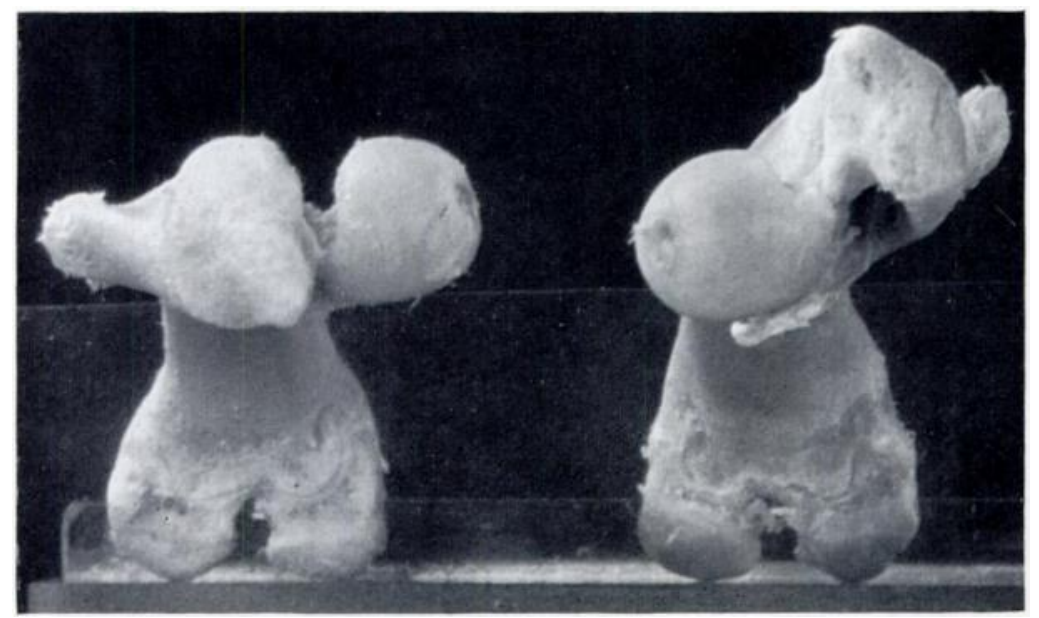

Fig. 4

Lorenz position. Splinting the left femur for fourteen weeks has produced no retroversion; but in the unsplinted femur $\mathbf{4 5}$ degrees of retroversion have occurred.

femoral anteversion still developed and was later associated with spontaneous dislocation of the hip. When the hip was flexed, instead of extended, a similar degree of anteversion developed. In all these positions medial rotation was the common factor.

In the second group are included those animals in which the effects of lateral rotation were studied. The animals could not balance with the hip in full lateral rotation when the knee was flexed. The leg was, therefore, splinted with the hip flexed and the knee extended; the hip was slightly abducted and the splinted limb was fixed under the trunk with an abdominal band. The rotational strain was produced and maintained by using the foot as a lever and including it in the plaster splint. The results (Table III) show a greater degree of retroversion in the splinted femur than in the normal.

In the third group are included those animals in which the hind limb was splinted in the Lorenz position. From the results (Table IV) it is seen that no retroversion developed in the splinted femur. Even the normal degree of retroversion was diminished as the duration of splintage increased. In one animal 5 degrees of anteversion were found, but this was probably due to a faulty technique. Table IV and Figure 4 show that increasing retroversion developed in the opposite femur; such changes will be discussed later.

Fig. 5

The posterior surfaces of the femora are painted to show the twist of the shafts. The left femur shows that most of the anteversion has developed in the distal metaphysis. The femur on the right is normal.

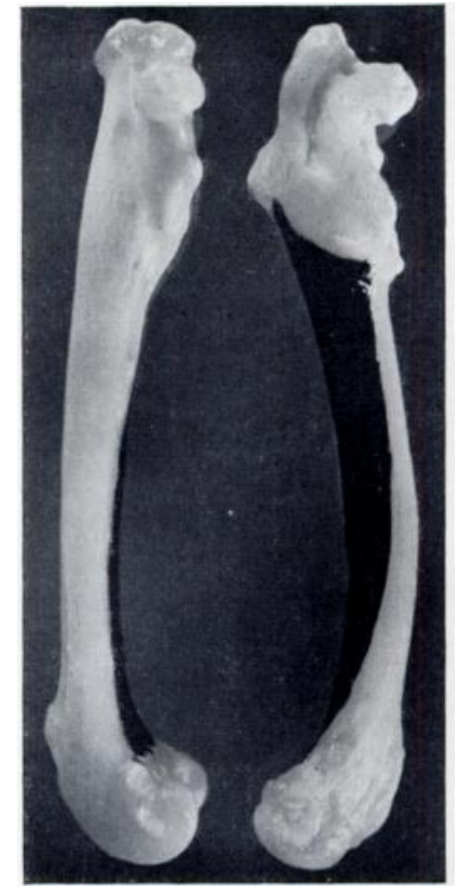

FiG. 5

VOL. 44 B, NO. 2, MAY 1962 
These three groups of experiments show that 1) prolonged medial rotation of the femur, whether the hip be flexed or extended, abducted or adducted, will produce anteversion; 2) prolonged lateral rotation of the femur, with the hip flexed and abducted, will increase retroversion; 3) prolonged fixation of the femur in the Lorenz position will correct-or prevent - the normal development of retroversion. The mechanism of this is discussed later.

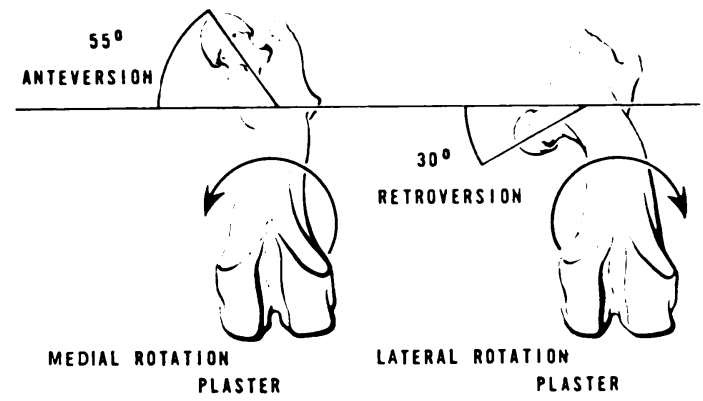

FIG. 6

Femoral rotational deformity in relation to deforming force (arrow).

Site and direction of deformity-In the simple rotational experiments the use of a plaster spica produced a rotational strain which was transmitted through the whole length of the femur. The deformity was found to occur mostly in that part of the bone which had grown during the experiment, that is, in the metaphysial regions (Appleton 1934, Arkin and Katz 1956).

TABLE V

Results of the First Experiment for the Correction of Anteversion

\begin{tabular}{|c|c|c|c|c|}
\hline Rabbit & . & 2 & 149 & 150 \\
\hline $\begin{array}{l}\text { Duration } \\
\text { splintage }\end{array}$ & and type of & 5 weeks medial & 15 weeks medial & $\begin{array}{r}5 \text { weeks medial } \\
10 \text { weeks Lorenz }\end{array}$ \\
\hline Degrees o & of anteversion & 30 & 50 & 5 \\
\hline
\end{tabular}

TABLE VI

Estimated Correction of Anteversion in Both Experiments

\begin{tabular}{|c|c|cc|}
\hline Rabbit & $\begin{array}{c}\text { Duration of } \\
\text { Lorenz plaster } \\
\text { (weeks) }\end{array}$ & $\begin{array}{c}\text { Degrees of } \\
\text { anteversion }\end{array}$ & $\begin{array}{c}\text { Degrees of } \\
\text { correction }\end{array}$ \\
\hline 350 & 20 & 10 \\
\hline 348 & 15 & 15 \\
\hline 345 & 10 & 20 \\
\hline 150 & 5 & 25 \\
\hline
\end{tabular}

All the animals spent the first five weeks in medial rotation, with an estimated development of approximately 30 degrees of anteversion.

A very slight abnormal twist also occurred in the original diaphysis. The degree of deformity in the distal metaphysis was twice that in the proximal metaphysis, as shown in Figure 5. This distribution of deformity reflects the relative growth rates of the distal and proximal femoral epiphyses (60 per cent and 30 per cent respectively) as described by Gill and Abbott (1942). 
Appleton (1934) and more recently Arkin and Katz (1956) performed similar experiments but they were more concerned with the effects of rotational strain at the knee joint. Their plaster splints only extended to mid-thigh level, so changes occurring in the proximal ends of the splinted femora were considered to be secondary. In principle, the findings were similar in that the rotational deformity was in the opposite direction to the deforming force (Fig. 6).

\section{CORRECTION OF ANTEVERSION EXPERIMENTS}

The simple rotational experiments suggested that the Lorenz position corrected femoral retroversion, so the following experiments were done to observe its effects on anteversion. The experiments were performed in two phases. During the first phase the limb was splinted

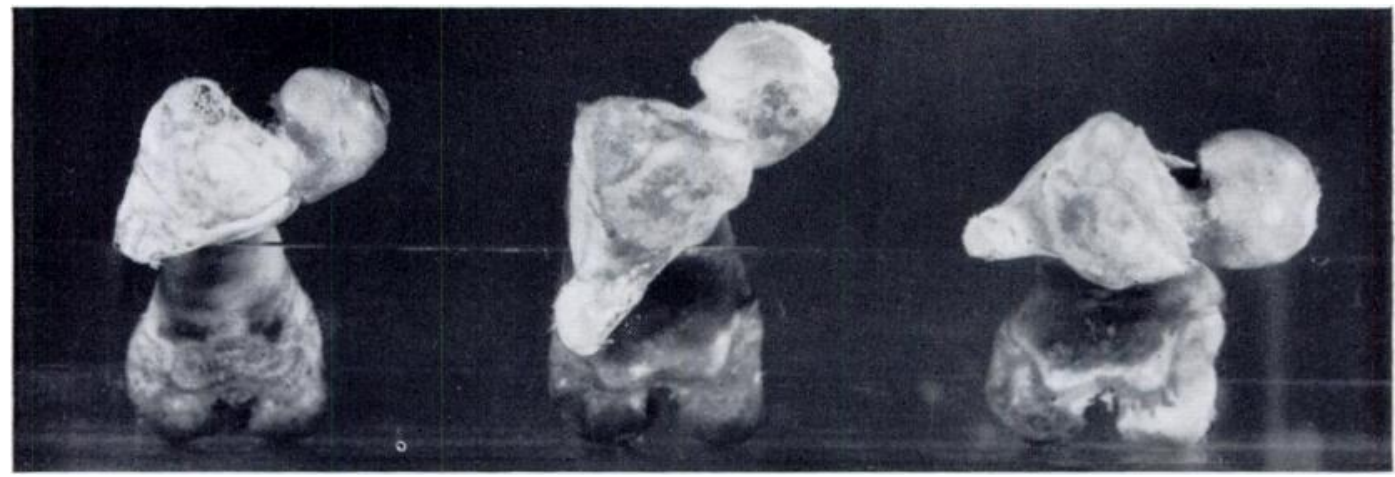

FIG. 7

The results of the first experiment for the correction of anteversion. Left: after five weeks of splinting in medial rotation. Centre: after fifteen weeks of medial rotation. Right: after five weeks of medial rotation and ten weeks in the Lorenz position.

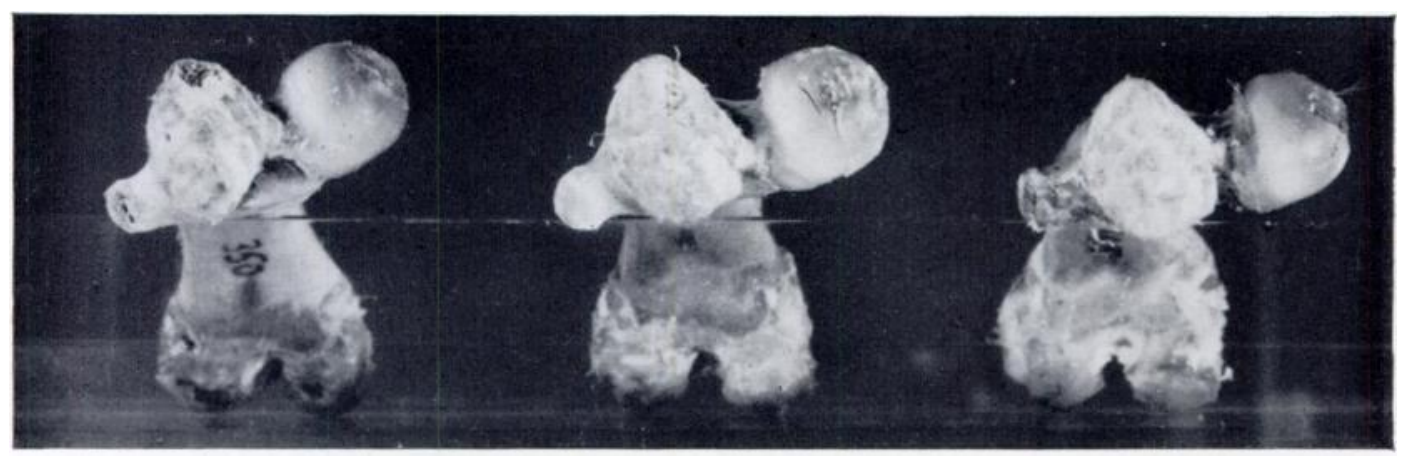

Fig. 8

In the second experiment for the correction of anteversion the three animals were splinted in medial rotation splints for the first five weeks and then in the Lorenz position for (from left to right) four, six and seven weeks respectively.

in medial rotation to produce anteversion. In the second phase the thigh was gradually abducted and flexed to 90 degrees and the lower leg was brought into line with the trunk, the neutral position of Lorenz.

The first phase lasted five weeks. Previous experiments in five rabbits showed that medial rotation plasters of this duration produced at least 30 degrees of anteversion (values varied from 45 to 30 degrees). On the assumption that at least 30 degrees of anteversion existed in the splinted femora at the end of the first phase, the rotational changes which developed during the second phase could be estimated by measuring the degree of anteversion at the end of the experiment. 


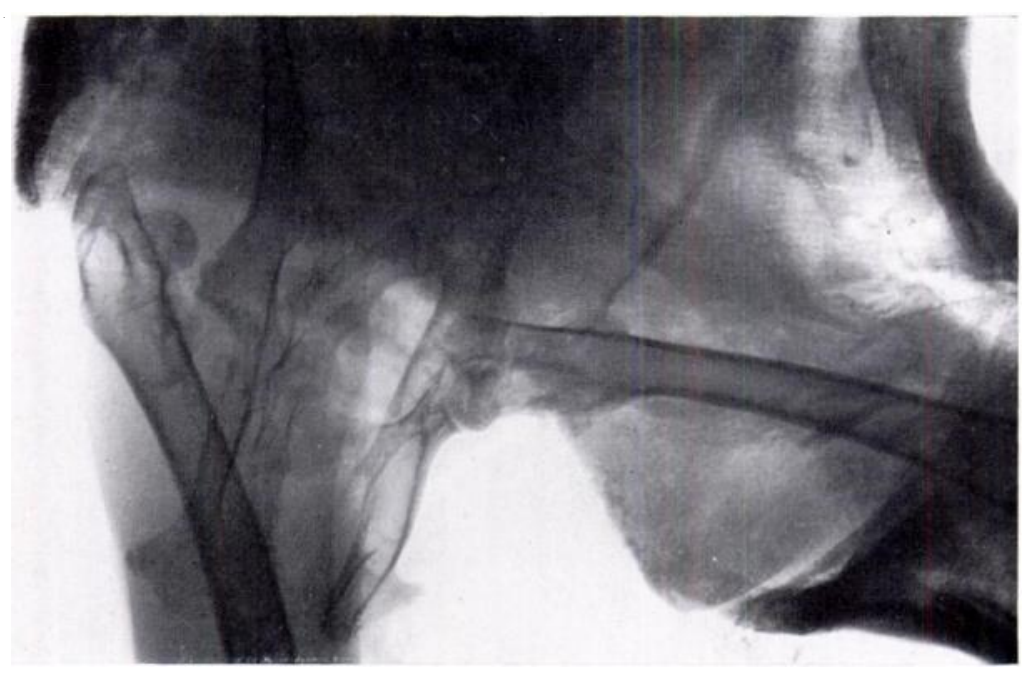

Fig. 9

Radiograph of rabbit with a dislocated right hip after the left leg had been splinted in medial rotation for six weeks.

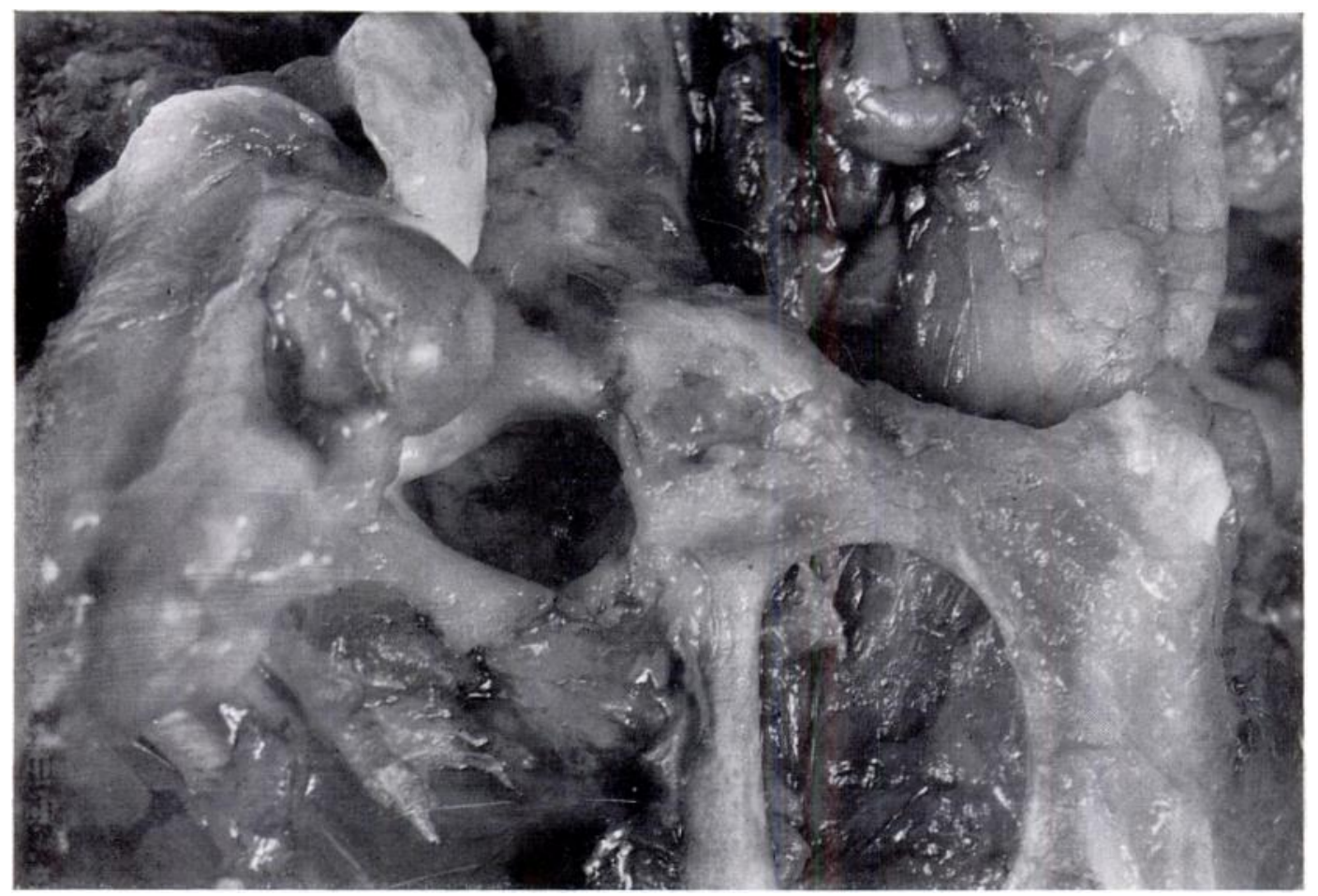

Fig. 10

Antero-superior dislocation of right hip which has been present for nine weeks. The acetabulum is triangular in shape and a false acetabulum has formed above. There is no limbus. There are 10 degrees of femoral anteversion. 
Two experiments were performed. In the first, two animals were used from the same litter. One animal was splinted in medial rotation for the first and second phases (fifteen weeks). The other was splinted in medial rotation for the first phase (five weeks) and in the Lorenz position for the second phase (ten weeks). Figure 7 and Table $\mathrm{V}$ show the results in these two rabbits compared with the femur of a third rabbit of the same age that had been splinted in medial rotation for five weeks. The anteversion in the first animal is estimated to

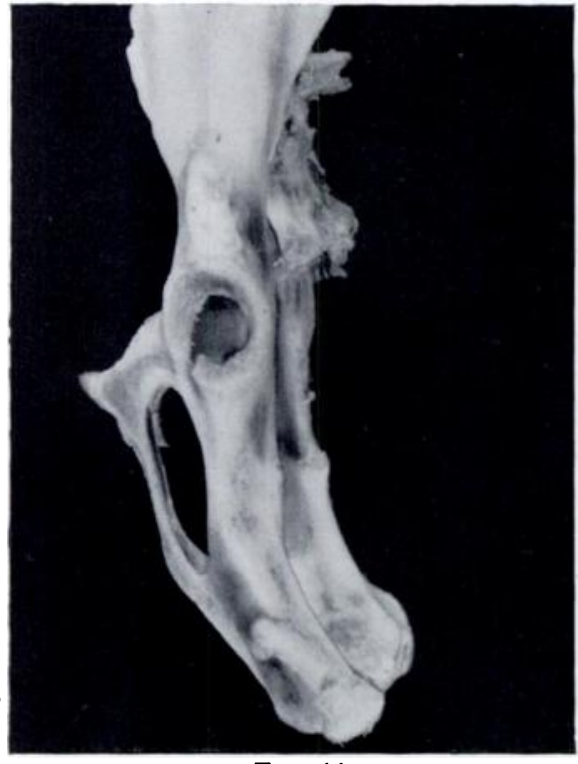

FIG. 11

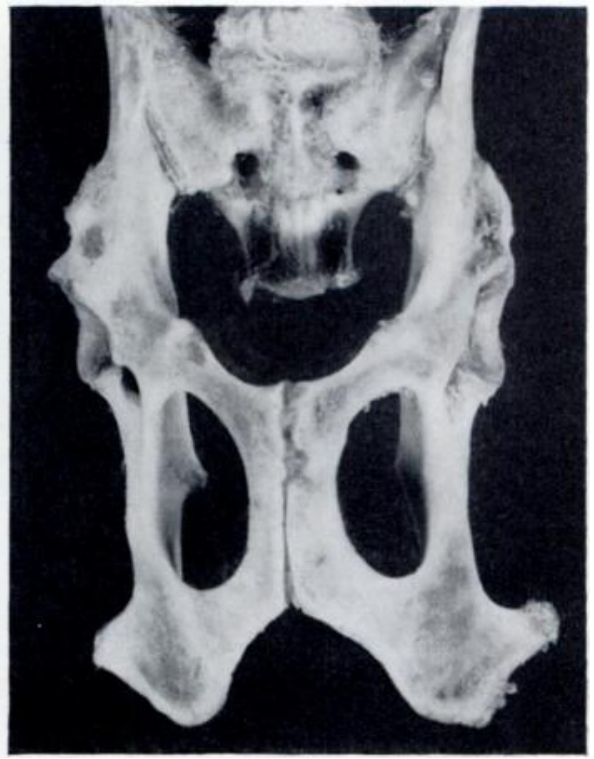

FIG. 12

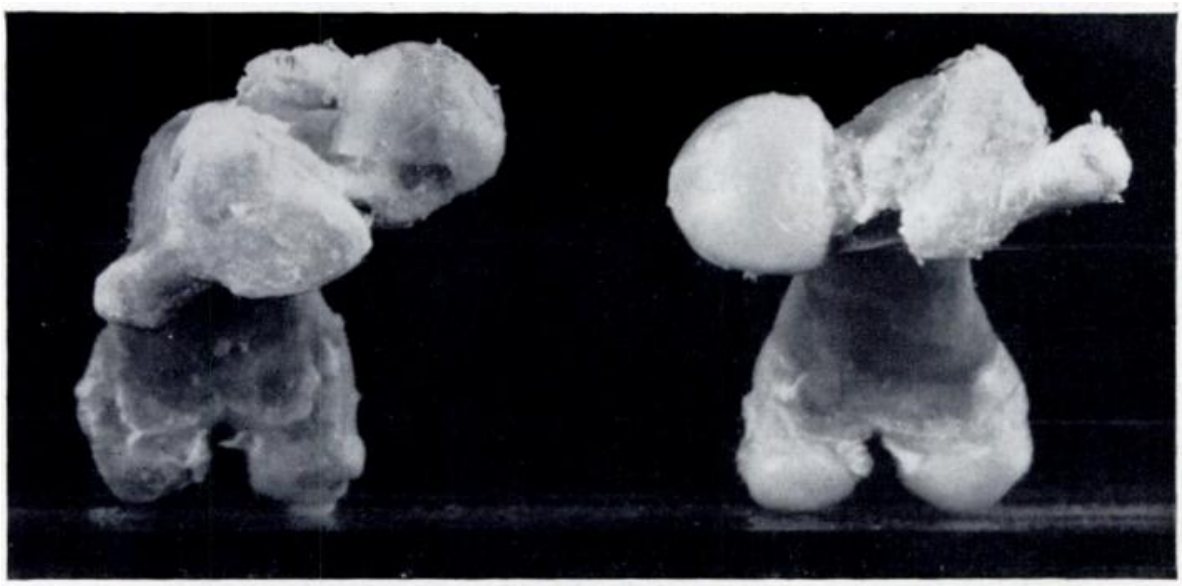

FIG. 13

Rabbit 317 after twelve weeks with the left leg in medial rotation splint. Figure $11-\mathrm{A}$ lateral view of the left acetabulum. Figure 12-An anterior view of the pelvis. The left acetabulum is oval and the anterior rim is shallow, giving the appearance of a more forward looking acetabulum. Figure 13-The femoral anteversion is 0 degrees on the right and 45 degrees on the left.

have increased from 30 to 50 degrees during the second phase, whereas the estimated anteversion in the second decreased from 30 to 5 degrees.

In the second experiment three rabbits were used from the same litter and the first phase again lasted five weeks. In the second phase all the plasters were changed to the Lorenz position and maintained in the first rabbit for four weeks, in the second rabbit for six weeks and in the third rabbit for seven weeks. The results, shown in Figure 8 and Table VI, suggest

vOL. 44 B, NO. 2, MAY 1962 
that, during the second phase, a gradual correction of the pre-existing anteversion was obtained by the Lorenz plasters. The mechanism of this correction will be discussed later.

\section{EFFECTS ON THE OPPOSITE FREE LIMB}

In the rabbit the normal hip posture is flexion, abduction and lateral rotation. The femoral anteversion that is present at birth changes to retroversion by the time the animal is skeletally mature. The following experiments show that any mechanism which changes the

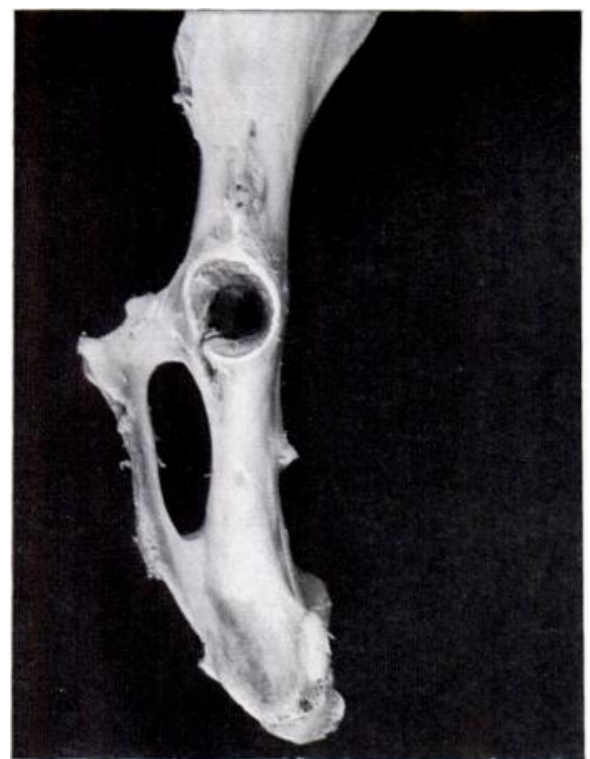

FIG. 14

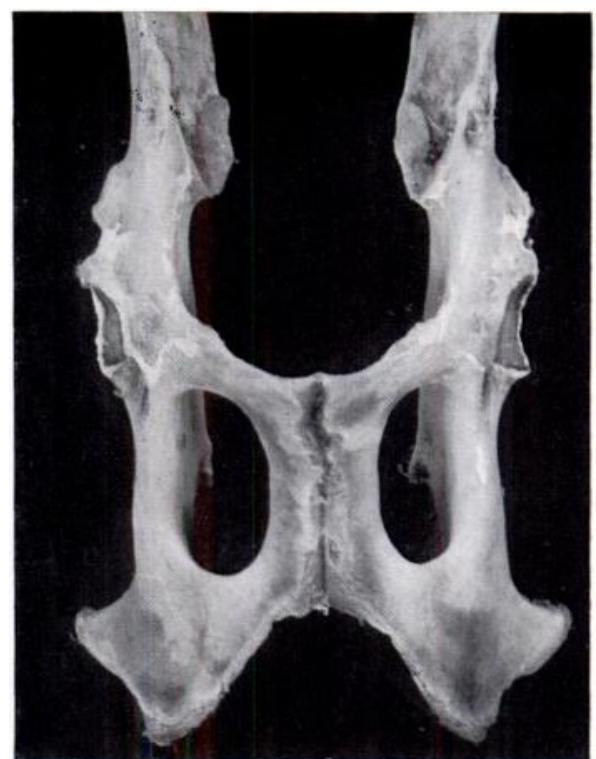

FIG. 15

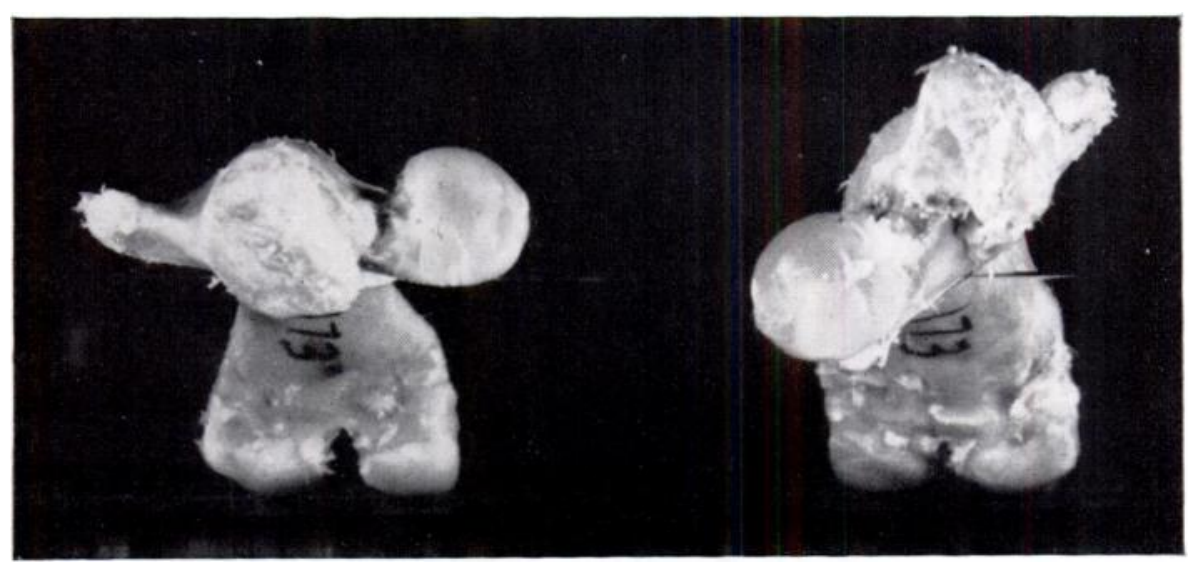

FIG. 16

Rabbit 173 after fourteen weeks with the left leg in the Lorenz position. Figure 14-A lateral view of the left acetabulum. Figure 15-An anterior view of the pelvis. The left acetabulum is not oval but circular and there is no dysplasia of the anterior rim. Figure 16-The femoral retroversion is 40 degrees on the right and 5 degrees on the left.

normal posture may produce variations in the normal twist of the femur. When the left leg was splinted in medial rotation the right leg assumed a posture of flexion, adduction and medial rotation. Table II shows that the normal development of retroversion in the right femur was prevented and later anteversion developed. In four animals, after six weeks in plaster, the right hip dislocated. This was shown by a change in the posture of the limb: 
the hip and knee hyperextended and the thigh was rotated laterally. Radiographs at this time confirmed the dislocation (Fig. 9). At necropsy the femoral head was found to be above and in front of the acetabulum (Fig. 10).

When the left leg was splinted in the Lorenz position the right leg assumed a posture of flexion, adduction and lateral rotation. Table IV shows that the normal degree of retroversion developed and later became exaggerated. Spontaneous dislocation did not occur in the presence of retroversion.

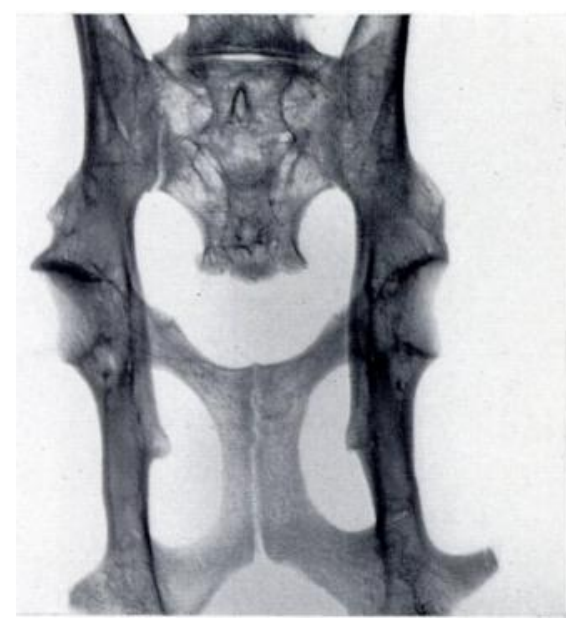

FIG. 17

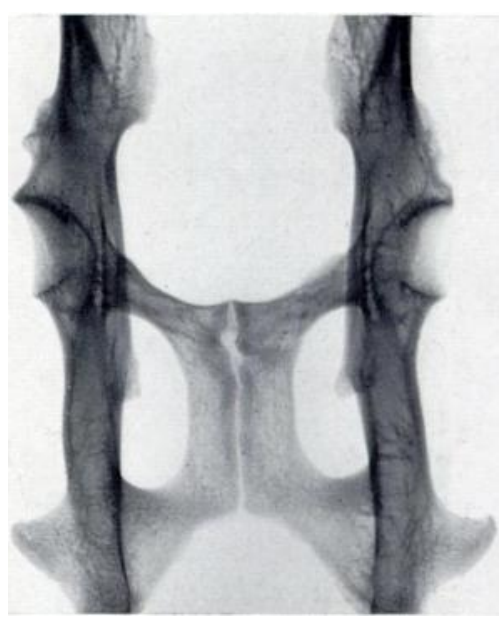

FIG. 18

Radiographs of the pelves of rabbits 317 (Fig. 17) and 173 (Fig. 18).

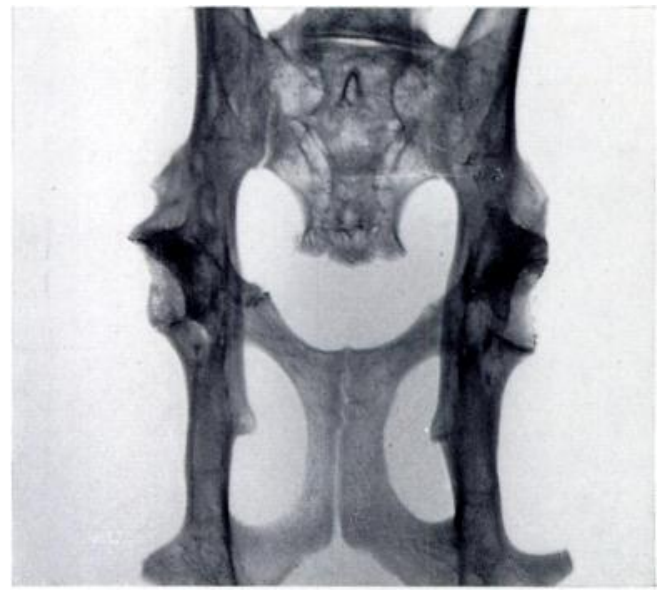

FIG. 19

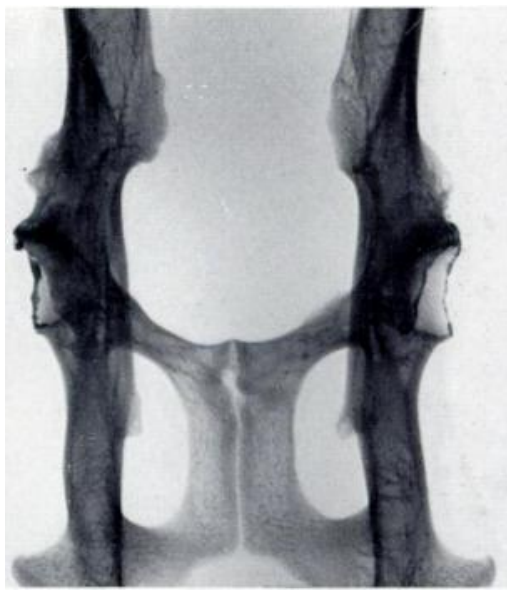

FIG. 20

Radiographs of the same pelves in Figures 17 and 18 but with the ilio-pectineal area coated with barium paste. Figure 19-In rabbit 317 the anterior rim of the left acetabulum is narrower than the right. Figure 20In rabbit 173 the two anterior rims are of equal width.

Appleton (1934) also studied changes in the opposite femur brought about by " accommodative postures." After division of the lateral rotators of one hip, he observed that the opposite limb was held in lateral rotation and that the femur became retroverted. At this point the findings differ in the two series but the experimental conditions are dissimilar. It is interesting that Appleton described dislocation in a hip after division of its lateral rotators. 


\section{ACETABULAR CHANGES}

In view of the claims as to the effectiveness of various methods of splinting on acetabular development, the acetabular changes occurring in these experiments have a special interest.

In all animals the pelvis, acetabulumand femur on the splinted side were slightly smaller than on the opposite side. These changes were probably due to the immobilising effects of the plaster splints.

A significant dysplasia was found in the acetabula of limbs splinted in medial rotation but was absent in limbs splinted in the Lorenz position. The dysplastic acetabulum is more oval in shape and appears to face more anteriorly because of the shallow anterior rim (Figs. 11 to 16). The dysplasia produces a narrowing of the pelvis, immediately above the ilio-pectineal eminence (Figs. 17 to 20 ).

\section{DISCUSSION}

Le Damany (1908) described femoral anteversion as being the prime factor in anterosuperior dislocation of the hip. Badgley (1949) believed anteversion to be a reciprocal deformity with acetabular dysplasia, caused by the failure of the lower limb to rotate medially during the dynamic development of the hip. The study of congenitally dislocated hips in neonatal necropsy specimens has failed to confirm the presence of anteversion (Fairbank 1930, McFarland 1956) and so its importance as a dislocating factor has not been upheld. Many who still believe in its presence now hold that it is a deformity secondary to the dislocation developing post-natally. Foetal anteversion is, therefore, generally thought to be an uncommon deformity. It may, however, be produced by the internal rotation malposition of an extended breech posture and may then give rise to post-natal dislocation.

Bernbeck (1952) splinted the hind legs of kittens in medial rotation and produced femoral anteversion. His observations have been confirmed by our experiments, which have also demonstrated that anteversion can be produced by a persistent posture of internal rotation in the free unsplinted limb. Posturally induced anteversion was later associated with anterosuperior dislocation of the hip. Such changes are also seen in young children with spastic hemiplegia and paralytic spina bifida, in whom the affected hip may assume a posture of flexion, adduction and medial rotation. Femoral anteversion, with or without dislocation, can occur in pyogenic arthritis of the hip, and it is not an uncommon complicating factor in

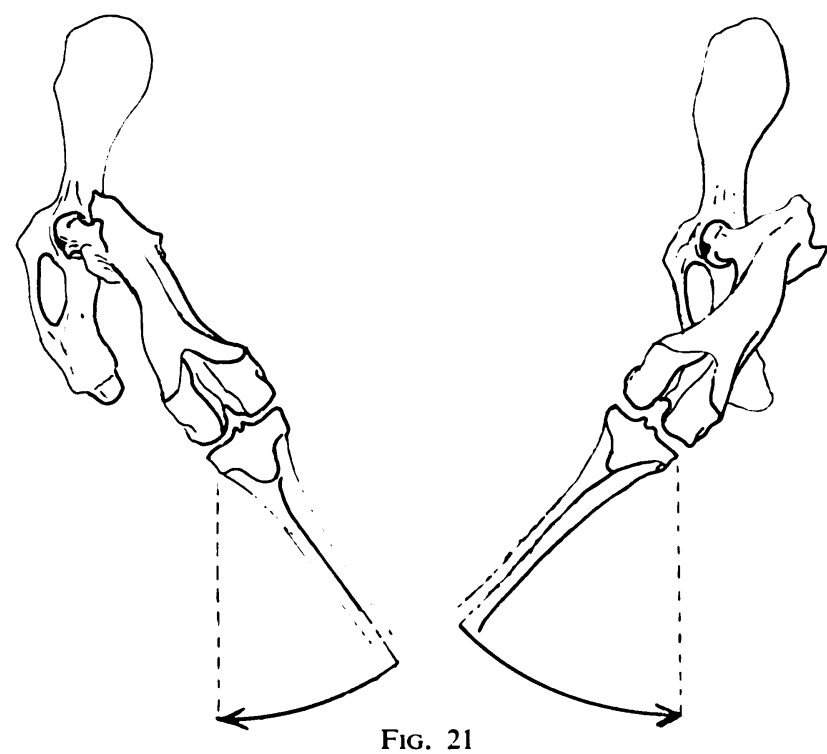

The mechanism of the Lorenz position. The vertical broken lines represent the neutral position. The anteverted femur shown on the left has to be laterally rotated to bring the tibia into the neutral position and, similarly, the retroverted femur on the right must be medially rotated.
Still's disease (McFarland 1956). In all these cases anteversion is produced by the strain of medial rotation on the femoral epiphysis and it develops whether the femoral head is in or out of its socket.

In the treatment of congenital dislocation of the hip femoral anteversion is recognised as the main cause of residual subluxation following the removal of medial rotation splints (Somerville and Scott 1957, Trevor 1958, Batchelor 1959). In the light of our experiments this is not surprising, because it has been shown that splinting in medial rotation produces anteversion and anterior dysplasia of the acetabulum. These two deformities will produce anterior dislocation of the femoral head when the hip is extended. The assumption that 
changing the position of a medial rotation splint from extension to flexion brings about a reversal of the moulding forces on the femoral head (Batchelor 1959) is not confirmed by our experiments. Medial rotation produces anteversion whether the hip is extended or flexed.

Those who maintain reduction of the femoral head by splinting in the Lorenz position do not appear to be troubled by anteversion (Fairbank 1930, McFarland 1956, Wilkinson and Carter 1960). Experimentally the femur splinted in medial rotation develops anteversion and when splinted in lateral rotation develops retroversion. Yet when splinted in the Lorenz position any previously existing anteversion or retroversion is corrected. A study of Figure 14 reveals the mechanism of the Lorenz position. When an anteverted femur is flexed and abducted it has to be laterally rotated to bring the tibia into the same plane as the trunk (Fig. 21). The extent of the lateral rotation required depends on the degree of anteversion present. The lateral rotation strain corrects the anteversion. The same mechanism applies to the retroverted femur which has to be medially rotated to bring the tibia in line with the trunk. The medial rotation strain corrects the retroversion.

Thus the rotational force required to bring the limb into the true Lorenz position will automatically tend to correct any anteversion or retroversion which might be present.

\section{SUMMARY}

1. Sustained medial rotation of the hind limb in the immature rabbit produces femoral anteversion and acetabular dysplasia.

2. Sustained lateral rotation produces retroversion.

3. Splinting the hind limbs in the Lorenz position corrects both anteversion and retroversion.

4. The mechanism of the Lorenz position is discussed.

It gives me great pleasure in thanking $\mathrm{Mr}$ H. J. Seddon, Mr C. W. S. F. Manning, Mr D. L. Evans and Mr G. C. Lloyd-Roberts for their kind advice and criticisms during the preparation of this paper. The experience and skill of Mr Joseph Cioch, Senior Animal Technician, greatly contributed to the success of the experiments which were performed in the Wellcome Research Laboratories at the Institute of Orthopaedics; the cost was met by a grant from the Joint Clinical Research Committee of the Royal National Orthopaedic Hospital and Institute of Orthopaedics. I am indebted to the Photographic Department of the Royal National Orthopaedic Hospital for the photographs and to the Photographic Department of the Westminster Hospital for the drawings.

\section{REFERENCES}

Appleton, A. B. (1934): Postural Deformities and Bone Growth. Lancet, i, 451.

Arkin, A. M., and KATZ, J. F. (1956): The Effects of Pressure on Epiphyseal Growth. Journal of Bone and Joint Surgery, 38-A, 1,056.

BADGLEY, C. E. (1949): Etiology of Congenital Dislocation of the Hip. Journal of Bone and Joint Surgery, 31-A, 341.

Batchelor, J. S. (1959): Congenital Dislocation of the Hip. Proceedings of the Royal Society of Medicine (Section of Orthopaedics), 52, 910.

Bernbeck, R. (1952): Zur pathologischen Anatomie und funktionellen Pathologie der Hüftverrenkung und des Luxationsbeckens. Archiv für orthopädische und Unfall-Chirurgie, 45, 268.

Fairbank, H. A. T. (1930): Congenital Dislocation of the Hip: with Special Reference to the Anatomy. British Journal of Surgery, 17, 380.

Gill, G. G., and Aввotr, L. C. (1942): Practical Method of Predicting the Growth of the Femur and Tibia in the Child. Archives of Surgery, 45, 286.

Le Damany, P. (1908): Die angeborene Hüftgelenksverrenkung. Ihre Ursachen-Ihr Mechanismus-Ihre anthropologische Bedeutung. Zeitschrift für Orthopädische Chirurgie, 21, 129.

McFarland, B. (1956): Some Observations on Congenital Dislocation of the Hip. Journal of Bone and Joint Surgery, 38-B, 54.

Mackenzie, I. G., Seddon, H. J., and Trevor, D. (1960): Congenital Dislocation of the Hip. Journal of Bone and Joint Surgery, 42-B, 689.

Somerville, E. W., and Scott, J. C. (1957): The Direct Approach to Congenital Dislocation of the Hip. Journal of Bone and Joint Surgery, 39-B, 623.

Trevor, D. (1958): Osteotomy in the Treatment of Congenital Dislocation of the Hip. Proceedings of the Royal Society of Medicine (Section of Orthopaedics), 51, 1,045.

Wilkinson, J., and CARTER, C. (1960): Congenital Dislocation of the Hip. Journal of Bone and Joint Surgery, 42-B, 669.

vol. 44 B, NO. 2, MAY 1962 